\title{
Editorial
}

\section{Automation in the Virology Laboratory: Contribution to Improve The Viral Diagnosis}

\author{
Fernando Cobo*
}

\author{
Microbiology Unit. Area of Biotechnology, Hospital de Poniente, El Ejido, Almería, Spain
}

Automation in the microbiology laboratory has revolutionized the way in which the microbiologists can diagnose human pathogens, including viruses. Automated techniques are now commonly used to diagnose viral diseases and manage patients with these kinds of infections. The use of this technology at the viral laboratory has been facilitated by the introduction of a growing number of commercially available tests for viral diagnosis. Technological advances in molecular diagnosis such as real time-PCR techniques, nucleic acid sequencing, DNA microarrays and proteomics have quickly developed the virology field and created new opportunities for improve the diagnosis.

With regard to viral pathogens, the goals in performing virology automated techniques are to provide timely results useful for high-quality patient care at a reasonable cost. One of the main advantages of automated methods is that these techniques can be performed quickly if there are adequate laboratory resources. The development of rapid and sensitive diagnostic methods provides the opportunity to detect viruses at an early stage, so rapid results are associated with improvements in patients' diagnosis. Moreover, automation by mean of these above mentioned methods has dramatically reduced the dependency on culture-based methods.

The main purpose of the hot-topic about automation in the virology laboratory is to give an overview of the main automated techniques for the diagnosis of the most important viral diseases.

Dr. Avivar has provided a comprehensive review of the main strategies for the successful implementation of viral

*Address correspondence to this author at the Microbiology Unit. Area of Biotechnology, Hospital de Poniente, El Ejido, Almería, Spain;

Tel: +34950022638; E-mail: fernando.cobo.sspa@juntadeandalucia.es laboratory automation. He has analyzed the current situation of laboratories with regard the automation as well as their associated costs, reflecting new criteria and ideas for the organization of new biotechnology laboratories from his own point of view.

Dr. Cabezas-Fernández and Dr. Cabeza-Barrera have analyzed the current state of the art for the diagnosis of both hepatitis B (HBV) and hepatitis C (HCV) viruses, two of the most clinically relevant viruses, above all in our health area in which a high rate of immigrant population coming from Africa and Eastern European countries is present.

Dr. Álvarez et al. have reviewed the main systems for the diagnosis and monitoring of HIV infection, giving us an overview of the main aspects relating to the automated methods available for laboratory diagnosis as well as for monitoring of the HIV infection and determination of resistance to antiretroviral and viral tropism.

Furthermore, Dr. Ortiz et al. have provided a review about the current human papillomavirus (HPV) genotyping tests in order to diagnose this kind of viruses; these are considered important pathogens distributed worldwide mainly causing cervical cancer in women.

Meanwhile, Dr. Pérez-Ruíz et al. have reviewed the main advances in clinical virology for detecting respiratory viruses with automated methods.

Finally, this hot topic has been completed by an article focused on molecular diagnostic techniques for viral testing giving an up-to-date of the main nucleic acid methods and their clinical applications in this field.

Given the increase of the viral pathogens and taking into account associated economic data and costs for these determinations, I consider that these reviews represent a useful tool, providing updated information for those health care providers who were interested in this topic.

(C) Fernando Cobo; Licensee Bentham Open.

This is an open access article licensed under the terms of the Creative Commons Attribution Non-Commercial License (http: //creativecommons.org/licenses/by$\mathrm{nc} / 3.0 /$ ) which permits unrestricted, non-commercial use, distribution and reproduction in any medium, provided the work is properly cited. 